\title{
Poesía (en) Guaraní: la palabra dislocada*
}

\author{
Poetry (en) Guaraní: word dislocated
}

\author{
María Claudia Rodríguez Monarca
}

Universidad Austral de Chile, Facultad de Filosofía y Humanidades, Instituto de Lingüística y Literatura, Valdivia, Chile. Correo electrónico: claudiar@uach.cl

El artículo propone una lectura desde las nociones de dilingüismo y bilingüismo, de un repertorio de poemas guaraníes de Susy Delgado, Brígido Bogado y Mario Rubén Álvarez. La hipótesis del trabajo es que, si bien el uso de las dos lenguas en Paraguay parecieran apuntar a una experiencia bilingüe, lo hacen en realidad cubriendo campos semánticos y espacios culturales distintos (vedados a la otra lengua), dando cuenta de un dilingüismo. De esta manera, la palabra poética se erige como un lugar (locus) que posibilita la coexistencia de ambas lenguas, en doble codificación y, particularmente, en forma de collage etnolingüístico. La lengua jopará (tránsito entre el castellano y el guaraní), en el caso más radical, se instala en un tercer espacio estratégico de resistencia, en un espacio semántico mixto que recupera la autoafirmación identitaria y cultural.

Palabras clave: dilingüismo, collage etnolingüístico, tercer espacio, guaraní, jopará.

The article proposes a reading from the notions of dilinguismo and bilingual, a repertoire of poems Guarani from Susy Delgado, Brigido Bogado and Mario Ruben Alvarez. The working hypothesis is that while the use of two languages in Paraguay, seem to point to a bilingual experience, they do actually covering semantic domains and different cultural spaces (closed to the other language), accounting for a dilinguismo. In this way the poetic word stands as a place (locus) that enables the coexistence of both languages, double coding or ethnolinguistic collage. The language jopará (transit between Castilian and the Guarani), in the most radical, is installed in a third strategic area of resistance in a mixed semantic space, which retrieves the identity and cultural self-assertion.

Key words: dilinguismo, ethnolinguistic collage, third space, Guarani, jopará.

Este trabajo es parte del proyecto Fondecyt $N^{\circ}$ 1100662, "Repertorios en coexistencia e interferencia en la poesía indígena hispanoamericana actual”, del que soy investigadora responsable, cuyo objetivo es estudiar los repertorios más que un corpus de autores y textos, como modelos poéticos que operan en la poesía indígena. 


\section{ENTRE DOS LENGUAS}

Entre dos lenguas, tu elemento es el silencio El silencio de los políglotas Julia Kristeva

En un despertar /se pegó /a mi lengua estalló / en mi boca, / cosa insospechada, el habla. / Cosa tiernísima, / buena de verdad, / aliento del cielo, que nos da la vida /un momentito, / en medio de la noche AyvuMembyre. Hijo de aquel verbo Susy Delgado

El artículo propone como hipótesis central, a partir del corpus de tres poetas, que si bien el uso de dos lenguas en Paraguay (guaraní y castellano) pareciera apuntar a una experiencia bilingüe, lo hace en realidad cubriendo campos semánticos y espacios culturales distintos (vedados a la otra lengua). A este fenómeno lo ha llamado Bartomeu Meliá (1990), dilingüismo. Esto significa que los sujetos que manejan ambos códigos (sin importar cuál sea su lengua materna) no tienen posibilidad de utilizarlos de manera indistinta en los diferentes contextos sociales, y se torna privativo, por ejemplo, el castellano en los espacios gubernamentales y protocolares. ${ }^{1}$ El reconocimiento de este fenómeno no es visto, sin embargo, como negativo por otros autores, como el escritor Rafael Barret (2006), que plantea que el manejo simultáneo de las dos lenguas "robustecerá y flexibilizará el entendimiento". No se chocan, ni son opuestas, sino que se complementan, al poder abarcar entre ambas todos los espacios posibles. Como dice Barret, "Se toman por opuestas cosas que quizás se completen. Que el castellano se aplique mejor a las cuestiones de la cultura moderna ¿quién lo duda? Pero ¿no se aplicará mejor el guaraní a las relaciones individuales, estéticas, religiosas de esta raza y de esta tierra?” (29).

Sobre esta restricción y desplazamiento territorial del guaraní ${ }^{2}$ hay innumerables estudios, del que destacamos el de Delicia Villagra-Batoux (2002) que analiza el proceso diacrónico de la lengua, desde el guaraní prehispánico, en un marco de oralidad monolingüe, hasta la asunción de la escritura y la lengua literaria, proceso que conlleva al guaraní paraguayo, como una lengua influenciada, que manifiesta su capacidad de adaptación (no de absorción, sino de innovación cultural). Este fenómeno también es objeto de disputa entre ambas escuelas lingüísticas y se torna aún más dramático cuando se discute desde el propio guaraní culto (y con rasgos de estaticidad) sobre la pertinencia del guaraní paraguayo (más dinámico, transdiscursivo

Meliá (1971) reconoce que este fenómeno viene ya desde el mundo colonial: “una lengua viene a ser dominada cuando se la relega al coloquio íntimo y se le niega vigencia en lo que se ha dado en llamar el mundo de la cultura. El guaraní recubría ciertas áreas de la vida social; el castellano, otras”. Esta situación se mantuvo en los comienzos de la república, en el proceso de independencia de Paraguay, como señala y se pregunta en otro texto Meliá (2010a): "Los paraguayos y paraguayas de los días de la Independencia tenían el guaraní como lengua propia y casi única en sus pueblos, en la casa y en la calle, ¿por qué toda la documentación oficial de la época está en castellano? Somos lo que hablamos. ¿En qué lengua se tomó conciencia de la independencia en el Paraguay?” (25).

\footnotetext{
A pesar de estas restricciones del guaraní que va demostrando Meliá en la Colonia y la República, un terreno propio es el de las guerras del Chaco y de la Triple Alianza; como señala Amaral (2005), en ambas "el guaraní idiomático fue un soldado invisible, custodio y vigía de su propia trinchera”.
} 
y transcultural) como la lengua de enseñanza en las escuelas. ${ }^{3}$ A pesar de esta presión, el guaraní paraguayo ha dado la batalla por no quedar restringido al uso coloquial e informal. La supervivencia o presencia de la lengua indígena, aunque en situación de diglosia, es posible; ${ }^{4}$ pensemos en todos los esfuerzos que dieron fruto para ver salir una ley de lenguas el año 2010 y la creación de un Ministerio de Lenguas. Incluso, desde una perspectiva más osada, David Galeano (2011) ha llegado a proponer que el guaraní redujo al castellano: "la Lengua Guaraní permaneció viva e indomable pese a las más increíbles formas de opresión y represión que padeció. Podemos afirmar que con todo en contra y con casi nada a favor -así y todo- el Guaraní redujo al Castellano". ${ }^{5}$

Confluye también otra variante entre lenguas (así como el guaraní paraguayo y el español paraguayo): la lengua jopará, tránsito entre el castellano y el guaraní; es un guaraní dislocado, desplazado y, con ello, superpuesto, mixturado, influenciado, dinámico, propio de los procesos culturales de contacto. Wolf Lustig (1996), estudioso de la lengua y literatura guaraní, lo define como una mezcla de lenguas:

El jopara es lenguaje entremezclado de español y guaraní en el cual gran parte de los paraguayos se comunican día a día. Se ha caracterizado como la tercera lengua del Paraguay, y no sería exagerado llamarlo la lengua general de este país sudamericano, aunque en sentido estricto escapa a la condición de una lengua. Probablemente es más adecuado describirlo como una mezcla de lenguas que como lengua mezclada. Se define precisamente por su "falta de normatividad [...] que desafía cualquier categorización (Meliá, 1992)." El jopara se nos presenta como una zona de interferencia de borrosos límites, difícil de captar y de describir, entre el guaraní paraguayo (cuyo perfil nos servirá de base para explicar algunos rasgos del jopara) y el español paraguayo, que también ha integrado muchos rasgos —incluso estructurales— del guaraní (Lustig 1996: 19).

Esta lengua híbrida es el caso más radical de manifestación de la escritura poética, bajo la modalidad textual de collage etnolingüístico (Carrasco 1991, lo mismo que doble registro), y se instala como tercer espacio estratégico de resistencia, en un espacio semántico mixto, que recupera la autoafirmación identitaria y cultural.

Hasta aquí hemos presentado un excurso necesario que es el antecedente sobre la lengua guaraní y su relación con la lengua castellana, que pareciera que en la vida social no logran encontrarse sino ocupar espacios distintos. En este escenario la palabra poética se erige como un lugar que posibilita la coexistencia de ambas lenguas.

El primer antecedente de poesía escrita en ambas lenguas (guaraní-castellano) es de Natalicio Talavera (1839-1867), situado en el romanticismo paraguayo. Su particularidad no reside solamente, según Amaral, en que escribe en doble registro sino en que mantiene el "acento epigramático” de la lengua materna guaraní (por la característica aglutinante propia de la lengua), y no se restringe a imitar y adoptar los moldes europeos.

A propósito de la escuela, Susy Delgado (2005a) hace mención a la incorporación tardía de la literatura guaraní al canon pedagógico, a través de los programas de estudio de la educación primaria y secundaria.

4 De esta polémica, instalada también desde el Ateneo de la Lengua, da cuenta el artículo de Batomeu Meliá (1999).

5 David Galeano (2011) va a concluir que el Guaraní se sumerge y perturba profundamente la locución castellana, a través de un riguroso estudio de cuatro fenómenos lingüísticos. 


\section{LA LITERATURA GUARANÍ DE PARAGUAY ${ }^{6}$}

Pensar en la literatura paraguaya, y más aún en la guaraní, desde fuera de Paraguay, resulta una incógnita. La invisibilización de esta producción pareciera dar cuenta de su inexistencia o al menos de una escasa presencia de autores, de movimientos y tendencias literarias relevantes. Susy Delgado en la Introducción de 25 nombres capitales de la Literatura Paraguaya, consciente de ello escribirá: “Con este libro, queremos hacer un pequeño aporte a este proceso de reivindicación de la literatura paraguaya, que pasa en primer lugar por el conocimiento” (2005: 5). Por tanto, para los autores, estudiosos y críticos literarios de Paraguay, el problema parece ser de otra naturaleza, vinculado a los circuitos de divulgación y de desvinculación con las grandes editoriales que abarcan un amplio radio de difusión y que suelen publicar a los autores latinoamericanos. Frente a este fenómeno encontramos una producción restringida en términos de tiraje y de divulgación (destacan editoriales como El Lector, Manuel Ortiz Guerrero, Surucuá y Servilibro), pero fecunda en cuanto a creación (particularmente revistas y cancioneros, ya que permiten recuperar textos que se encuentran dispersos e inéditos). Sin embargo, esta producción no va siempre a la par de una crítica literaria. ${ }^{7}$ Esto último se puede explicar, además, por el periodo gris que vivió Paraguay desde 1940, año en que es intervenida la Universidad Nacional. Se ha denominado a este periodo "la etapa autoritaria (1940-1989)", principalmente con las dictaduras del general Morínigo (1940-1947) y de Stroessner (1954-1989). ${ }^{8}$

Respecto a la literatura paraguaya, coinciden los críticos y estudiosos actuales que este sistema literario tiene la particularidad de ser la expresión de una "nación bilingüe y bicultural” (Teresa Méndez Faith 2004). ${ }^{9}$ Este será un criterio fundamental de selección de autores y textos en las antologías, historias y diccionarios poéticos paraguayos y marcará, precisamente, una diferencia significativa con la manera de

${ }_{6} \quad$ Al referirnos a Paraguay tenemos que aclarar que constituye uno de los países de la zona cultural guaraní. La noción de zona cultural, a pesar de reconocer elementos transversales y suprafronterizos, que conforman semiósferas culturales, no puede definirse sino a partir de los países que la configuran. Lo común, paradojalmente, comienza a ir de la mano de las diferencias dadas por la división geopolítica que fragmenta una "nación indígena" en etnias, comunidades y aldeas, y que se ven expuestas a nuevas influencias, relaciones e interferencias propias del diálogo, más o menos tensionado, con la cultura y las literaturas particulares de cada país. En el caso de la nación guaraní, encontramos, incluso, una organización sociopolítica que la reconoce y en la que participan representantes de diferentes comunidades y organizaciones guaraníes de los distintos países (Argentina, Paraguay, Bolivia y Brasil) y que abogan, entre otras cosas, por el reconocimiento del guaraní como lengua oficial del Mercosur. Sin embargo, se torna difuso demarcar esta zona cultural cuando nos detenemos en los procesos migratorios y los innumerables casos de exilio. Como escribe la propia Susy Delgado (2005a): "el arisco rompecabezas de la región guaraní que quería bocetar, aunque sea a grandes rasgos, se me destartaló definitivamente, como una bolsa de bolitas caída de las manos".

7 Una dura crítica a la falta de crítica literaria la realiza Raúl Amaral (1995) al señalar, al comienzo del prólogo de El júbilo difícil, antología de Carlos Villagra Marsal, preparada por el propio Amaral, que la difícil ubicación de la poesía paraguaya se debe "al predominio de la improvisación sobre el método y al imperio de la anécdota por sobre la búsqueda investigativa, seria y pertinaz de las verdaderas raíces de la expresión nacional en el mundo” (1995: 7).

8 Esta extensa época de oscurantismo no contribuyó de manera alguna, como señala Rivarola (2010), en la educación superior universitaria, por la intolerancia y persecución que mantuvo con relación a los valores académicos y al pensamiento crítico: "El rasgo más llamativo del régimen moriniguista fue la sostenida confrontación con el estamento universitario. Un gran número de docentes fueron separados de sus cátedras, otros perseguidos o exiliados”.

9 Antes que la lengua y la cultura, está la conciencia de que “el Paraguay sin Guaraníes es muy poca cosa” (Meliá 2010). 
constituir (y canonizar) las literaturas nacionales de los otros países del continente, en las que las voces indígenas no comparten el mismo espacio cultural y literario (o entran tardíamente a ese circuito). Delgado señala:

Nuestra selección no podía eludir el doble perfil lingüístico de la literatura paraguaya, que en justicia debía expresarse en la inclusión de escritores de las dos lenguas que se hablan y escriben en Paraguay: el castellano y el guaraní (2005: 6).

Rubén Bareiro Saguier le dedica el capítulo final del libro de la Colección Ayacucho, La Literatura guaraní del Paraguay (1980) a la discusión de la relación entre la tradición guaraní y la literatura paraguaya, poniendo en duda la legitimidad de reescribir la tradición ancestral y mítica desde coordenadas contemporáneas, resultando versiones y adaptaciones libres que terminan cambiando lo esencial del relato original, como hace, según Bareiro, Augusto Roa Bastos. Asimismo, encontramos otros críticos y poetas que reflexionan sobre el carácter bicultural y bilingüe de esta producción, como Rudi Torga y Serafin Francia en su antología 13 Creadores nacionales (1993), Luis María Martínez en El Trino Soterrado (1985), y en la profusa obra de Bartomeu Meliá, Teresa Méndez Faith, Carlos Villagra, Rubén Bareiro, Pedro Encina, Raúl Amaral, entre otros.

Respecto a la literatura, una salvedad significativa es la distinción que hacen los propios críticos/poetas y antropólogos, como Lino Trinidad, Bartomeu Meliá y Miguel Ángel Fernández, entre poesía guaraní (expresión auténtica de la poesía autóctona y que reproduce el sonido de la voz indígena) y poesía en guaraní (de fuerte influencia de la poesía castellana), que se clasifica, a su vez, según Rubén Bareiro, Carlos Villagra y Lino Trinidad, en poesía popular y culta. De esta manera, resulta interesante observar una serie de fenómenos como:

1) la relación entre literatura culta y literatura popular en correspondencia con la producción literaria guaraní. Esto es, el modo cómo se ha asimilado la tradición popular de origen hispánico en las propias culturas indígenas.

2) En el caso de la poesía guaraní, hay que partir desde la premisa que se considera como tal una poesía escrita en lengua guaraní (ésta, como lengua franca, no es condición suficiente para definir una literatura indígena) y que puede ser traducida por los mismos autores. La propia Susy Delgado (2005) señala que no se puede eludir al doble perfil lingüístico de esta literatura. Este texto, como muchas de las antologías, las historias de la literatura y los diccionarios de literatura paraguaya (de Rudy Torga, Pedro Encina, Luis María Martínez, Sara Delicia Villagra, Teresa Méndez-Faith, Rubén Bareiro y Carlos Villagra, entre otros), contemplan en su repertorio (es decir, intentan canonizar) a poetas que escriben en guaraní y en versión bilingüe.

3) La relación entre poesía y música, ${ }^{10}$ o escritura y canto, en tanto el repertorio de las literaturas indígenas nos muestra un amplio espectro entre la escritura y la

10 Respecto a la vinculación directa de la palabra poética con la música, ya Rudi Torga en la Introducción a la Antología de las mejores poesías en guaraní (1998), señalaba que esta poesía salió a la vida llevada de la mano de la música. Por eso, resulta natural encontrar poetas músicos y poetas musicalizados (como el CD de música paraguaya del tenor Jorge Castro, quien musicaliza 16 poemas de poetas guaraníes). El caso más emblemático es José Asunción Flores, seguido de Teodoro Mongelos, Manuel Ortiz Guerrero y Félix Fernández, entre otros. El soporte sonoro es utilizado también para difundir poesía recitada, como el trabajo “Ñe’êpotyguararíme” (CD de 17 poemas guaraníes). 
música (como el diálogo entre poesía, música y cancioneros), que va mucho más allá de la relación entre oralidad y escritura.

4) Un interesante fenómeno de la crítica paraguaya es la estrecha vinculación entre literatura y estudios de la lengua (fenómeno similar a los estudios de la literatura andina quechua y aymara). Los grandes lingüistas son considerados también críticos literarios.

5) El reconocimiento como punto de partida y antecedentes etnoliterarios para la literatura guaraní, de los aportes de los antropólogos que supieron escribir y recopilar "desde el punto de vista de los nativos" los relatos míticos celosamente guardados. Nos referimos al alemán Kurt Unkel (bautizado por los indígenas guaraníes como Nimuendaju), que publicó en 1914 Los mitos de la creación y destrucción del mundo como fundamento de la religión de los Apapokúva-Guarani; el etnólogo León Cadogan, con Ayvu rapyta ${ }^{11}$ (Fundamento de la palabra de 1959) y los textos recopilados en La palabra luminosa: mitos y cantos sagrados de los guaraníes (1974), escrito por el francés Pierre Clastres. En los tres autores queda en evidencia cuán esencial es la palabra y la lengua para el guaraní, pues allí está (al decir de Viveiros de Castro) el locus, la preservación del modo de ser guaraní.

Este locus este lugar supone relaciones con otros seres, objetos u otros lugares (Merrell 1998). Soja propone la noción de Tercer Espacio como una manera de pensar sobre la espacialidad fuera del pensamiento dicotómico.

\section{SEMIÓTICA Y TERCER ESPACIO}

Una sutil pero significativa (para los efectos de este trabajo) distinción hace la Semiótica del Espacio entre espacio y lugar. ${ }^{12} \mathrm{Al}$ primero lo define (desde la noción de primeridad de Peirce), como mero ser físico, sin relación alguna con otro, como "el modo de significación de lo que es tal como es, sin referencia a otra cosa" (Merrell 1998: 52). Lugar, por el contrario, supone relaciones con otros seres, objetos u otros lugares mismos, lo que lo dota de un sentido más específico.

Para Lotman (1996), la cultura se construye sobre la base de dos lenguajes primarios: la lengua natural y el modelo estructural del espacio. Sobre este último explica que toda actividad humana está ligada a modelos clasificatorios del espacio, a su división en propio y ajeno; en culto e inculto (caótico), en espacio de los vivos y espacio de los muertos, en sagrado y profano, etcétera. Del mismo modo, a cada espacio le corresponden sus habitantes (dioses, hombres, fuerzas

Recordemos algunos versos de este hermoso himno y texto fundacional del pueblo guaraní: "El verdadero padre Ñamandú, el primero,/de una parte de su propio ser de cielo.../ conoció para sí mismo la fundamental palabra que había de ser.../ por haber ellos asimilado ya el fundamento de la palabra y del amor,/ por haber ellos asimilado ya las series de palabras del canto esforzado,/ a ellos, por eso mismo, los llamamos:/ excelsos verdaderos padres de las palabras,/ excelsas verdaderas madres de las palabras” Ayvu Rapyta, de León Cadogan.

12 Esta discusión se instala también en la arquitectura, como se puede observar en el artículo de Patricio De Stefani (2009), quien postula que se ha reducido la concepción de ambos conceptos al suponer una visión abstracta del espacio frente a una concreta del lugar, al "espacio se lo ha propuesto como la esencia de la arquitectura pero ha derivado en una abstracción formal y vacía, obviando sus dimensiones sociales, simbólicas y políticas. Como crítica a este espacio abstracto y deshumanizado, los lugares de la arquitectura fueron catalogados como fenómenos concretos que afectan de manera directa al ser y al cuerpo humano en su totalidad. Sin embargo, algunos intentos por trabajar a partir de esta noción, han derivado igualmente en conceptos abstractos, reduccionistas y esquemáticos”. 
malignas). Sin embargo, dirá Lotman, para que un sistema responda a las funciones semióticas, "debe poseer mecanismos de multiplicación reiterada del objeto que constituye su significado". De esta manera, todo tipo de división de los espacios forma construcciones homomórficas, por tanto cada estructura interna reproducirá el universo, teniendo su espacio ‘propio’ y ‘ajeno', y contemplando en su interior, precisamente esa diferencia.

Hemos revisado la distinción entre espacio y lugar, entendiendo al lugar como un tipo de espacio situado, contextualizado, con referencia y sentido particular, al establecer relaciones con otros lugares. También desde la semiótica vemos cómo ese espacio particular, a su vez, reproduce en su interior los espacios propios y ajenos, lo identitario y la otredad. Este pensamiento dicotómico se desmonta o completa, en realidad, desde la noción de tercer espacio.

Soja propone la noción de Tercer Espacio (derivada, a su vez, del trabajo de Lefebvre), como una manera de pensar sobre la espacialidad fuera del pensamiento dicotómico. El Tercer Espacio es el elemento que completa la triada y, al mismo tiempo, engloba el Primer Espacio (el espacio material, empírico) y el Segundo Espacio (el espacio concebido). El Tercer Espacio se refiere a los espacios vividos o espacios de representación, los cuales son principalmente marginales, pero también espacio de resistencia, "que guía nuestra búsqueda del cambio emancipatorio y la liberación de la dominación” (Soja 1996: 70). El tercer Espacio será como un contraespacio del espacio hegemónico o del espacio ajeno que origina; es decir, un espacio que desafía el statu quo, entiéndase también como lengua y literatura canónica (Rodríguez 2005).

\section{4. ÑE’EPORÁ: LA PALABRA COMO LUGAR}

Fernando Aínsa (2006) en sus Propuestas de geopoética, se refería al desplazamiento del topos al logos a propósito de los espacios o "lugares posibles" para el despliegue de un imaginario geográfico en el denominado, entonces, Nuevo Mundo. La propuesta, en este trabajo, es identificar ambos conceptos (el logos en tanto topos), entender que para la cultura guaraní, la palabra es el lugar y la palabra en esa lengua (guaraní mixturado, jopará, lengua dislocada) constituye tanto ese lugar de resistencia, como el lugar de sentido del plano religioso, el locus que posibilita preservar el modo de ser guaraní.

El investigador más riguroso de la cultura guaraní, vigente, es el antropólogo y sacerdote jesuita Bartomeu Meliá. Señala él, en el capítulo "La palabra lo es todo" del libro Elogio de la lengua guaraní (1995), que:

Quien ha encontrado palabras buenas lo ha encontrado todo. Sí; el Guaraní es una cultura de la palabra (ñe’ e porá); esto es, del decir, del decirse, del ser dicho. Toma asiento una palabra cuando un nuevo ser es engendrado, toma pie en la morada terrenal la palabra cuando nace, el Guaraní es su palabra cuando recibe su nombre. Muere aquel de quien se le separa la palabra. La vida del Guaraní se define a sí misma en función de una palabra singular y única que hace lo que dice (...). Para los Guaraníes el alma no se da enteramente hecha, sino que se hace con la vida de la persona y el modo de su hacerse es su decirse. Toda la vida del Guaraní se estructura para ser fundamento y soporte de palabras verdaderas. La creación del mundo y del hombre son vistas como palabras dichas y participadas. Crimen y castigo del Guaraní es quedarse sin las palabras. 
Si para la cultura guaraní la palabra es el lugar, será en realidad un lugar de indeterminación, y un proceso dinámico y evolutivo de confluencia, aunque tensionada, de distintos espacios, las dos lenguas, guaraní y castellano, que tendrán que repensarse en su relación, precisamente como estrategia de resistencia.

\section{BREVIARIO DE LOS AUTORES Y UN TRAZADO DE SUS VERSOS}

El corpus de poetas coincide en que la experiencia vital y cotidiana será decidora en el momento de la escritura, decantando principalmente por temas vinculados al territorio y a la palabra. Tanto Brígido Bogado como Mario Rubén Álvarez pasaron parte de su infancia al alero y el calor de hogar de una comunidad rural y familia guaraní. Ambos sufrieron tempranamente el desarraigo por trasladarse a la ciudad.

Brígido Bogado, luego de estudiar filosofía, decide regresar a su tierra a recuperar la cultura de sus padres y reconstruir su identidad como integrante de este pueblo. En el 2007 publica Canto de la tierra. En el poema "Soy el hombre que se vuelve avá”, dirá:

He vuelto,

he dormido,

he soñado,

ese soy yo

un indígena que vuelve de la ciudad

a encontrarse con sus raíces.

Su proyecto poético es, desde el desarraigo, la recuperación de su esencia guaraní (su ser $a v a ́$ ) y el único modo que encuentra es volviendo a ese espacio, a ese hábitat, como el propio deambular del pueblo guaraní tras la búsqueda de "la tierra sin mal”:

Después de la hecatombe.

Despojado de mis tierras ancestrales,

Voy sin rumbo

Sin saber de mi destino...

Sin saber de un lugar

Donde realizar mi jeroky, mi tangará

Y volver mi alma

A Ñande Ru Kuery,

Porque estar como estoy...

Es no estar y no ser.

Errancia, ajenidad, extranjería, son los angustiosos sentimientos que provoca el despojo. La construcción de su ser avá queda a medio camino ¿Qué es un guaraní sin tierras, sin cantos? Dirá Meliá, “Nosotros somos geografía. La geografía también configura nuestra alma, por lo tanto cuando nos cambian la geografía, nos cambian el suelo que pisamos, entonces nosotros cambiamos”. Qué voz le queda al poeta, qué lugar, cómo se reinventa su avá. Escribe Bogado:

Tu voz... semilla que nace

Germinando de la muerte

En el silencio de tu danza. 
La resiliencia es propia del pueblo guaraní, por ello esta voz surge desde la muerte y el silencio. El oxímoron semilla muerte es la contradicción inherente, la totalidad contradictoria que no se resuelve ya en la palabra guaraní de los abuelos, sino en la palabra mestiza, el guaraní castellanizado y escrito, lejos de la sonoridad del viento y del canto ancestral.

Por su parte, Mario Rubén Álvarez, poeta bilingüe, periodista y docente, ha sido en varias ocasiones galardonado y siempre recuerda su formación en el taller Manuel Ortiz Guerrero, donde publicó parte de su obra. En 1992 apareció La sangre insurrecta, su primer poemario. Ha editado cuatro volúmenes de Las voces de la memoria, y en el 2007 A flor de ausencia, texto escrito en castellano y guaraní, algunos textos en “doble registro” y otros sólo en guaraní o sólo en castellano.

El poeta Tadeo Zarratea lo ha llamado el poeta de la nostalgia y es un acierto, en tanto que el modo de acceder al espacio perdido y añorado de la infancia es a través de la memoria que se cuela en el tiempo de lo cotidiano y lo hace con la palabra, a veces limitada, a veces muda, a veces fuego:

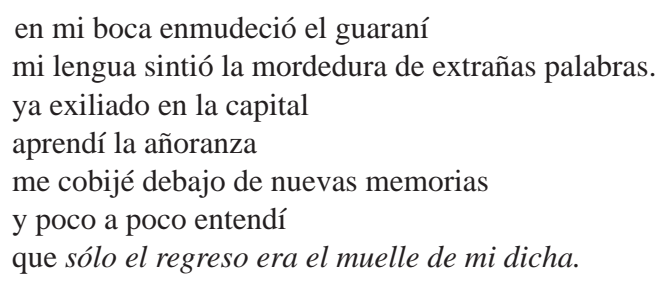

Pero ese viaje no llega a destino, la errancia, nuevamente, será parte entonces de la desdicha, como queda de manera muy clara en "Destino", poema que abre el lado castellano del libro:

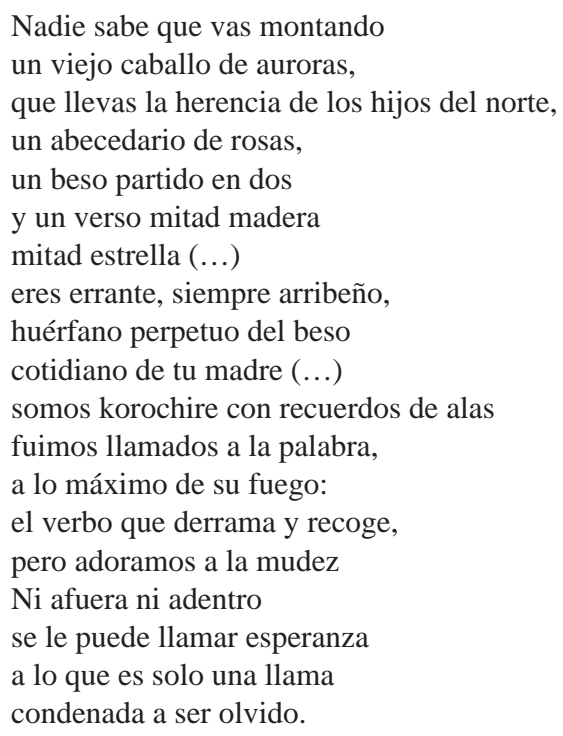

El sujeto errante, desterritorializado, tajado, partido, va perdiendo todos los referentes culturales y afectivos. Lo que parecía que le quedaba, la palabra, tampoco 
aflora y se queda en la mudez, pero sigue haciendo el intento de reinventarse en "Razones de la palabra”, "para no morirme de un síncope de silencio, para cantar guaranias en las noches sin estrellas... para eso elegí caer en la emboscada de la palabra”.

Susy Delgado, poeta, periodista, socióloga, crítica literaria y defensora de la lengua guaraní, actualmente encabeza la Dirección de Promoción de las Lenguas de la Secretaría Nacional de Cultura, en el Ministerio de Lenguas, creado recientemente tras la aprobación de la Ley de Lenguas el 2010. Su obra es extensa, tanto en su trabajo poético (desde Algún extraviado temblor, de 1986 a Cuando se apaga el takuá, de 2010), como de recopilación en antologías, de divulgación y de estudios críticos, en un ambiente y país donde no se desarrolla suficiente investigación sobre literatura guaraní en los espacios académicos, y sí se percibe el compromiso y estudio desde el ámbito de la lengua (como el trabajo que realiza el Ateneo de la Lengua, el Portal guaraní o La Fundación YvyMarãe'ỹ ("Tierra sin mal”, institución que vela por la vigencia, enseñanza y difusión del idioma guaraní, presidida por el lingüista Miguel Ángel Verón). Los estudios críticos de poesía guaraní los encontramos en los propios poetas, reflexión metatextual que pone énfasis precisamente en la lengua, en su indisolubilidad con la palabra poética; por tanto, su reconocimiento como tal y su estudio terminan vinculándose a los enfoques lingüísticos (mientras que, en el caso de la poesía mapuche, es frecuente el enfoque preferentemente literario para abordar esta producción). El interesante artículo de Susy Delgado "Poesía guaraní. La antigua búsqueda de la palabra-alma” (2006) da cuenta de esta relación. Allí señala que "Hablar de la poesía guaraní implica hablar de la lengua. La búsqueda de la palabra de los poetas paraguayos que cultivan este surco, es también la búsqueda de su propia lengua”.

Susy Delgado da cuenta de la preocupación por la palabra, leitmotiv de su obra poética y crítica, principalmente en AyvuMembyre. Hijo de aquel verbo (1999), que luego aparecerá en la antología Ñe' êjovái. Palabra en dúo (2005), y en su último libro Oguejavetakuapu. Cuando se apaga el takuá (2010). En Palabra en dúo (2005), escribe en la presentación:

Encontré... que era bueno mirar con ustedes esta palabra mía nacida en guaraní que halla su dúo en mi palabra castellana, porque observo de pronto que ellas hablan entre sí, porque el guaraní inicia el diálogo, o porque lo inicia el castellano como ocurre últimamente (...). Esta es mi Palabra en dúo que quiere crecer más, en diálogo profundo...

Señala Delgado que el guaraní inicia el diálogo, porque los dos primeros libros antologados fueron escritos primero en guaraní, y el tercero en castellano; todos ellos han sido traducidos por la propia autora, que es bilingüe y que quiere dejar de ser "dilingüe", esto es, expresarse desde dos lenguas que se manejan pero no dialogan. Ella se propone firmemente "crecer más en este diálogo profundo", pero lo dice varios años después de tomar conciencia que no puede ni ella misma traducirse. Afirma que "no sé traducir lo que me sucede", en Hijo de aquel verbo, texto que responde más a la estructura, la cosmovisión y la ontología de los textos y cantos míticos del Fundamento de la palabra. Este canto, verdadera elegía, es el llanto, pero también el grito y el dolor por querer y no poder encontrar su propio canto:

\footnotetext{
XI

En noche cerrada,

y en su oscuro fondo
} 


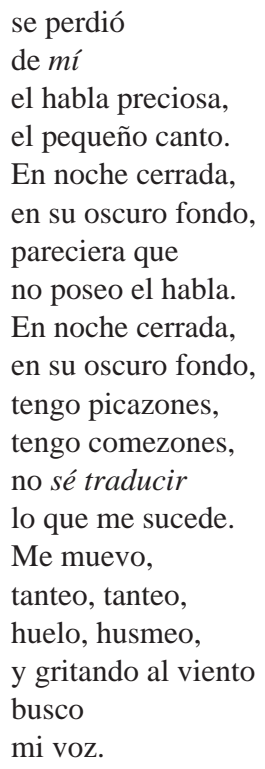

La palabra aquí es el lugar de lo sagrado pero también el espacio de resistencia intracultural, en el gesto homomórfico de reproducir el canto mítico. Desde esta búsqueda propia del alma, en tanto termina de hacerse en el decirse; desde la lengua como lugar que posibilita su concepción, su construcción, su parto, su ser guaraní, se repiensa, también, desde su lengua que muta:

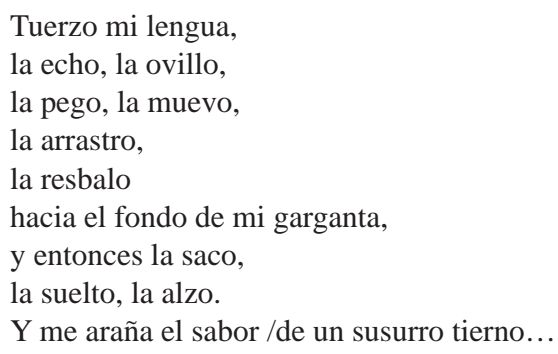

Su ser guaraní termina revistiéndose, como dice Meliá en el prólogo de Cuando se apaga el takuá (2010), de fuerza que proviene, tanto de su raíz profunda y milenaria, como de las experiencias, sensaciones y sentimientos del presente. "Una lengua que no sirve para decir nuestro ser y vivir de hoy no sirve para nada y está muerta (10)”:

Ay...si sucediera / que en mi alma despierte / el aliento, / que el habla despierte,

Ay, si sucediera / que el habla viviese / en la huella del habla / de mis antepasados.

Despierte ese hijo / del verbo, / la memoria.

La osadía de escribir en jopará, sabiendo el recelo que eso causa entre lingüistas puros de ambas lenguas y entre los escritores, vinculados al campo de poder, a la tradición y la cultura hegemónica, es el gesto precisamente de eso que buscaba, el 
diálogo profundo entre las dos lenguas. Para ello, la estrategia discursiva con la que cuenta es el collage, la superposición de lenguas, como queda en evidencia en “Purahéimo’a” (del libro Cuando se apaga el takuá):
Si yo pudiera hablar/ Ñandejára/ Si mi lengua supiera pronunciar ñe’éte
Si yo pudiera deshacer el alfabeto/del tiempo y la memoria cherespapysonga'uraka'e/ y amasara en mi boca ñe’éporájoguahami si descifrara el pentagrama de los vientos/ ajoraojokuáva che kú si pudiera convocar a los antiguos ayvujára/ oguerunga’ u chéve su dulce mimby si anidaran aquí che hay’ okuápe/ tojora che pytúpeokeva si me escucharan todos/ uminacherenduvéiva / si supiera cantar

Esta escritura es el gesto de la simultaneidad de los registros, pero también de la impureza, de lo mezclado, lugar que le permite, paradojalmente, renegar precisamente de esa palabra dislocada, de la imposibilidad de regresar a ese origen, al canto o de encontrar la tierra sin mal.

En el prólogo del Canto de la tierra de Bogado, Susy Delgado ya dimensiona el poder del canto: “entre el avá y el monte laten todavía los grandes secretos, la posibilidad de la armonía y la plenitud”, por eso, el canto es el tono final que queda, la oración, como la entendían los abuelos Guaraní.

\section{A MODO DE CONCLUSIÓN}

Los autores del corpus poético coinciden en una doble preocupación. Por un lado, el territorio (escindido), su lugar y, por otro, la palabra (mixturada). Es, precisamente, la escritura poética y el libro (como objeto) el espacio que posibilite el bilingüismo, esto es, la presencia simultánea o dialógica de ambas lenguas. Experimentan ellos en su escritura con una doble codificación, es decir, presentan los poemas en doble registro o en "collage etnolingüístico”. Esto último es ya una osadía, porque han optado por el uso de esta nueva lengua, el jopará, que no es lengua de prestigio, ni culta, ni menos a los ojos de sus pares una lengua literaria; pero es la lengua del presente, del diálogo; es el tercer espacio de resistencia, la trinchera que les permite manejar la doblez. Sin embargo, el gesto de diálogo profundo, a través del recurso del collage sólo ha dejado en evidencia la imposibilidad y la angustia de no tener dónde asirse (ni territorio ni palabra) y que, finalmente, la palabra no es más que una emboscada.

\section{OBRAS CITADAS}

Fuentes primarias:

Álvarez, Mario Rubén. 2007. Ñe'ẽ apytere (A flor de ausencia). Asunción: Servilibro.

Bogado, Brígido. 2007. Canto de la tierra. Asunción: Arandurã.

Delgado, Susy. 2010. Ogue jave takuapu. Cuando se apaga el takuá. Asunción: Arandurã. 2005. Ne é jovái (Palabra en dúo). Poesía bilingüe completa, con estudios críticos de Bartomeu Meliá, Susan Smith Nash, Víctor Casartelli, Martín Alvarenga, José Alberto de la Fuente, Carla Fernandes y Tracy Lewis. Asunción: Arandurã. . 1999. AyvuMembyre. Hijo de aquel verbo. Asunción: Arandurã. 
Fuentes secundarias:

Aínsa, Fernando. 2006. Del topos al logos. Propuestas de geopoética. Madrid-Frankfurt: Iberoamericana-Vervuert.

Amaral, Raúl. 1995. “La poesía natural y profunda de Carlos Villagra Marsal”. Prólogo de El Júbilo Dificil (poesía 1986-1995). Asunción: Don Bosco.

Amaral, Raúl. 2005. "La Patria poética”. Prólogo a Poesías del Paraguay. Antología desde sus orígenes. Asunción: Aramí Grupo Empresarial.

Amaral, Raúl. 2006. Escritos Paraguayos 1. Introducción a la Cultura Nacional. Edición digital corregida y aumentada. Asunción: BVP (primera edición 1984).

Bareiro Saguier.1980. La Literatura guaraní del Paraguay. Caracas: Ayacucho.

Bareiro Saguier, Rubén, et al. 2005. La diversidad poética del Paraguay. Asunción: Servilibro.

Bareiro Saguier, Rubén y Villagra Marsal, Carlos. 2007. Antología de la poesía culta y popular en Guaraní. Asunción: Servilibro.

Barret, Rafael. 2006. El dolor paraguayo. Asunción: Servilibro.

Carrasco, Iván. 1991. "Los textos de doble codificación. Fundamentos para una investigación”. Estudios Filológicos 26: 5-16.

De Stefani, Patricio. 2009. "Reflexiones sobre los conceptos de espacio y lugar en la arquitectura del siglo XX”, Diseño urbano y paisaje V, 16. En línea; disponible en http://www. ucentral.cl/dup/pdf/16_espacio_lugar.pdf

Delgado, Susy. 2005. 25 Nombres capitales de la literatura paraguaya - Compilación y selección. Asunción: Servilibro.

. 2005a. "De cuando el Añatuja desperdigó la región guaraní”. Texto leído en el Encuentro inter-regional de poesía Cerros de Oro, Andacollo, Chile, octubre, 2005.

. 2006. "Poesía guaraní. La antigua búsqueda de la palabra-alma”. Documentos Lingüísticos y Literarios 29. En línea; disponible en: http://humanidades.uach.cl/documentos_linguisticos/document.php?id=1236

Encina Ramos, Pedro-Tatajyva. 1997. Las cien mejores poesías en Guaraní. Asunción: Imprenta Salesiana.

Galeano, David. 2011. "El castellano reducido por el Guaraní”. Conferencia por el Día del Idioma Guaraní. Asunción: Ateneo de lengua y cultura Guaraní.

Lotman, Iuri.1996. La semiósfera I. Semiótica de la cultura y el texto. Madrid: Frónesis.

Lustig, Wolf.1996. “Mba’eichapa oiko la Guaraní? Guaraní y jopará en el Paraguay”. Papia 4, 2: 19-43

Martínez, Luis María.1985. El trino soterrado. Paraguay: aproximación al itinerario de su poesía social. Tomo I. Asunción: Intento.

Meliá, Bartomeu. 2010. "El Paraguay sin Guaraníes es muy poca cosa”. En diario Última Hora, Correo semanal 5. Sábado 25, diciembre de 2010. 2010a. "Independencia y Lengua”. Revista del Bicentenario 2, 2: 25-26. .1999. "El guaraní que nos une y el que nos desune”. Cuadernos Hispanoamericanos 589-590: 121-134.

. 1995. Elogio de la Lengua Guaraní. Asunción: Centro de Estudios Paraguayos “Antonio Guasch”.

1992. La lengua guaraní del Paraguay. Madrid: MAPFRE.

1990. Una nación, dos culturas. Asunción: Cepag.

1971. "El guaraní dominante y dominado”. Acción 11 (Septiembre).

Mendez-Faith, Teresa. 2008. Diccionario de la Literatura Paraguaya. Asunción: El Lector. . 2004. Antología de la Literatura Paraguaya. Asunción: El Lector. .1994. Breve Diccionario de la Literatura Paraguaya. Asunción: El Lector.

Merrell, Floyd. 2001. “Charles Peirce y sus signos”. Signos en Rotación, III, 181. En línea, disponible en: http://www.unav.es/gep/Articulos/SRotacion3.html

Rivarola, Domingo. 2010. Historia del pensamiento paraguayo 1940 - 1989. Asunción: El Lector. 
Rodríguez, Claudia. 2005. «Las “otras literaturas” de Latinoamérica. Criterios de inclusión y exclusión en el canon literario». Documentos Lingüísticos y Literarios 28: 77-81.

Siebenmann, Gustav. 1997. Poesía y poéticas del siglo XX en la América Hispánica y el Brasil. Madrid: Gredos.

Soja, Edward W.1996. Thirdspace. Journey to Los Angeles and Other Real-and-Imagined Places. Malden, Massachussets: Blacwell Publishers.

Torga, Rudi y Francia, Serafin. 1993. 13 Creadores nacionales. Asunción: Dirección de Cultura de la Municipalidad.

Torga, Rudi. 1998. Antología de las mejores poesías en Guaraní. Selección e Introducción. Asunción: El Lector.

Trinidad, Lino. 1998. Evolución Histórica del Idioma Guaraní y su situación en el MERCOSUR. Ciudad del Este: Edición Universidad Nacional del Este.

Villagra, Sara Delicia. 2002. El guaraní paraguayo: de la oralidad a la lengua literaria. Asunción: Expolibro. 